\title{
Smart Maximum-power-point Tracking Method for Photovoltaic Module Arrays Using Irradiation and Temperature Sensors
}

\author{
Kuei-Hsiang Chao, ${ }^{*}$ Yu-Hsiang Liao, and Ming-Chang Tseng \\ Department of Electrical Engineering, National Chin-Yi University of Technology \\ No. 57, Sec. 2, Zhongshan Rd., Taiping Dist., Taichung 41170, Taiwan
}

(Received March 28, 2018; accepted August 8, 2018)

Keywords: cerebellar model articulation controller, photovoltaic module array, maximum-power-point tracking, irradiation and temperature sensors

The purpose of this study was to develop a maximum-power-point tracking (MPPT) method for photovoltaic (PV) module arrays using a cerebellar model articulation controller (CMAC). Eighteen Sharp NT-R5E3E modules were used in a 9 series 2 parallel configuration. The power generation data at different sunlight intensities and array temperatures were used for obtaining training data. The slope of the power-voltage $(P-V)$ characteristic curves was used for tuning the weight of the CMAC during MPPT. This allowed the quantification and adjustment of the system and improved the tracking accuracy. The CMAC uses an algorithm that mimics the neural structure of the human cerebellum, and it has the ability to learn quickly, associate, and summarize. The time required for training was therefore relatively short, and this can increase the power generation of the PV module array. Some test results showed that tracking with this maximum-power-point (MPP) CMAC was perfectly feasible over a range of different temperatures and sunshine intensities.

\section{Introduction}

A photovoltaic (PV) power generation system consists of an array of PV modules, a power conditioner, and a power transmission and distribution system. Since the output power varies markedly with the intensity of sunlight and changes in ambient temperature, the power conditioner needs maximum-power-point tracking (MPPT) technology, in addition to a converter function, to control the PV module array so that it can operate at a maximum output power to minimize power loss.

Among existing conventional MPPT methods, the architecture of the perturb and observe $(\mathrm{P} \& \mathrm{O})$ method $^{(1)}$ is simple, requires the measurement of only a few parameters, and periodically increases or decreases the output voltage of the PV module array. In this method, the output voltage and output power before change are measured to determine the direction of the next disturbance. While this method does achieve MPPT, the work point swings around the MPP, resulting in energy loss. The constant voltage $\operatorname{method}^{(2)}$ has no complex formula, but measures

*Corresponding author: e-mail: chaokh@ncut.edu.tw https://doi.org/10.18494/SAM.2018.2059 
the MPP voltage before making an adjustment to the output voltage. Although the method achieves MPPT, the characteristics of the module change with age, and if the tracking reference voltage is not regularly adjusted, MPPT errors will arise. The rates of the changes in PV output power and voltage are used as the judgment logic in the power feedback method. ${ }^{(3)}$ This method has fewer disadvantages than the constant voltage method. However, in practical applications, rapidly changing atmospheric conditions cause measurement errors in the sensing elements and make it impossible to track the MPP properly. The judgment logic used in the incremental conductance method $^{(4)}$ is $d I / d V=-I / V$, wherein $V$ is the output voltage, $I$ is the output current, $d I / d V$ is the dynamic conductance, and $I / V$ is the static conductance. This tracking process is complicated and the system cost is high. Errors in the sensing elements can make it difficult or impossible to track the true MPP.

Recently, much more intelligent algorithms have been proposed for tracking the MPP. These include particle swarm optimization (PSO), ${ }^{(5)}$ the artificial bee colony $(\mathrm{ABC}){ }^{(6)}$ the genetic algorithm (GA), ${ }^{(7)}$ ant colony optimization (ACO), ${ }^{(8)}$ differential evolution (DE) ${ }^{(9)}$ and others like these. PSO is an algorithm based on observations of the social behaviour of birds, and can be used to solve problems involving search and optimization. ${ }^{(10)}$ All the moving particles have a fitness value corresponding to space, and each particle knows its own present fitness value and best position, known as the individual particle optimal value. This information can be likened to the experience owned by each particle, and each particle also knows all the best values and positions, that is, the global optimal value of the particles. Therefore, for each iteration update, correction and guidance from population experience can be used to update the individual velocity and position of the particles. Initially, all particles are scattered randomly across all areas. When a particle approaches the best target value in an area, the particles in that area will search for the best value, but the best solution for this area may simply be the local optimum. A search by particle groups then corrects the position of the optimal value and causes a population effect, which is close to the optimum for the whole domain. ${ }^{(11)}$ The ABC algorithm passes messages about size and direction, just like real worker bees pass messages to others by dancing in a pattern. ${ }^{(12)}$ To start with, random values are used and the search capacity is unstable. In the investigation stage, the selected number of colonies may also affect the steady-state performance and tracking speed. In the table of statistical results from PSO and $\mathrm{ABC}$ algorithms, ${ }^{(12)}$ it can be seen that the tracking time can reach 5 to $6 \mathrm{~s}$ and there is still room for improvement. Although the $\mathrm{GA}^{(7)}$ has the ability to find a global optimal solution, its dynamic response speed is still not sufficiently high. The ACO algorithm finds the optimal path, the pheromone update formula ${ }^{(13)}$ allows random searching to be avoided, and an optimal path can be found more easily. The pheromone update formula uses the exponential method to control the conversion between pheromone concentration and path length to a random value. Although this avoids the regional solution trap, experimental results show that exponential path calculations take a long time. DE resembles the GA, which uses real coding of specific races, and can search for the best value in the whole domain by calculating the variation through a difference and a one-to-one competitive survival strategy. However, this is only reached at the end of the simulation, ${ }^{(14)}$ and the strategy for individual mutation has a maximum of 5 items in accordance with the formula presented by Storn. This not only increases the tracking time 
during implementation, but the cross-coding and microcontroller encoding of the population require more accurate comparisons. ${ }^{(15)}$

The MPPT method proposed in this paper uses a cerebellar model articulation controller (CMAC) to excite memory in accordance with the size of the input signal. Similar input signals only excite similar memories, and the method uses direct memory addresses and stores the corresponding weight value. Because the input and output signals correspond to memory positions, a large amount of memory is needed. However, not all inputs store a weight as a memory. The signal input will obtain a memory excitation set via quantization, coding, and excitation address combinations. After weight value updating within excited memory addresses, the obtained output signal and the ideal signals are compared, and the average size of the error is then assigned to the excited memory address for tuning; this completes the overall training process.

\section{Output Characteristics of PV Module Array}

In this study, irradiation and temperature sensors were used to detect sunlight falling on a PV module array as well as the natural changes in intensity and temperature that take place. These changes cause variations in the current generated and this can be seen in the powervoltage $(P-V)$ and current-voltage $(I-V)$ output characteristic curves. The $P-V$ characteristic curves resulting from different amounts of sunshine and array temperature are shown in Figs. 1 and 2. In Fig. 1, the amount of sunlight ranges from 100 to $1100 \mathrm{~W} / \mathrm{m}^{2}$, and the position of the MPP in each case is different. Similarly, the MPP positions of the respective module temperatures are also relatively different. If a simple MPPT method is used, failure to track the MPP in time can easily arise.

\section{CMAC Algorithm}

A CMAC that can imitate the neural structure of the human cerebellum was proposed by Ablus in 1970. ${ }^{(16)}$ It was capable of both rapid learning and rapid response. This method was similar to other neural networks having both learning, training, and diagnostic capabilities. ${ }^{(17)}$

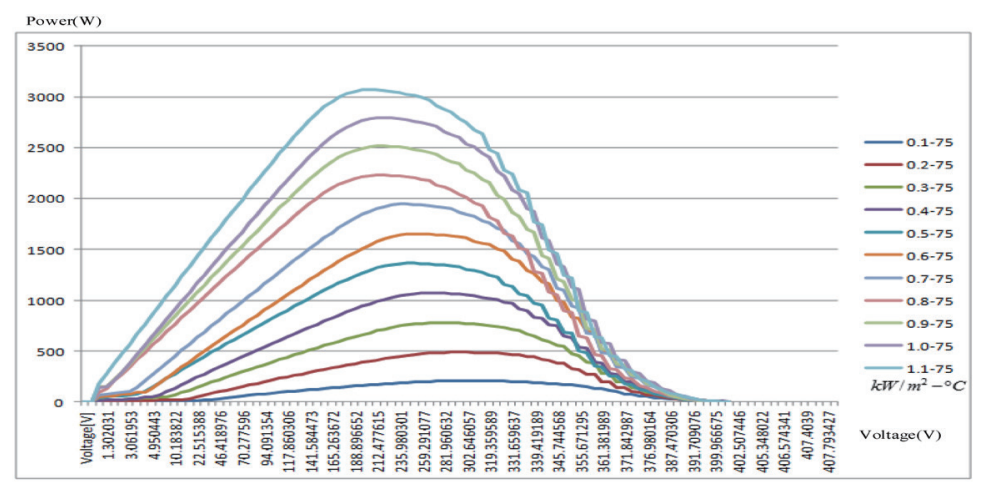

Fig. 1. (Color online) Photovoltaic module array $P-V$ curves at different sunlight intensities. 


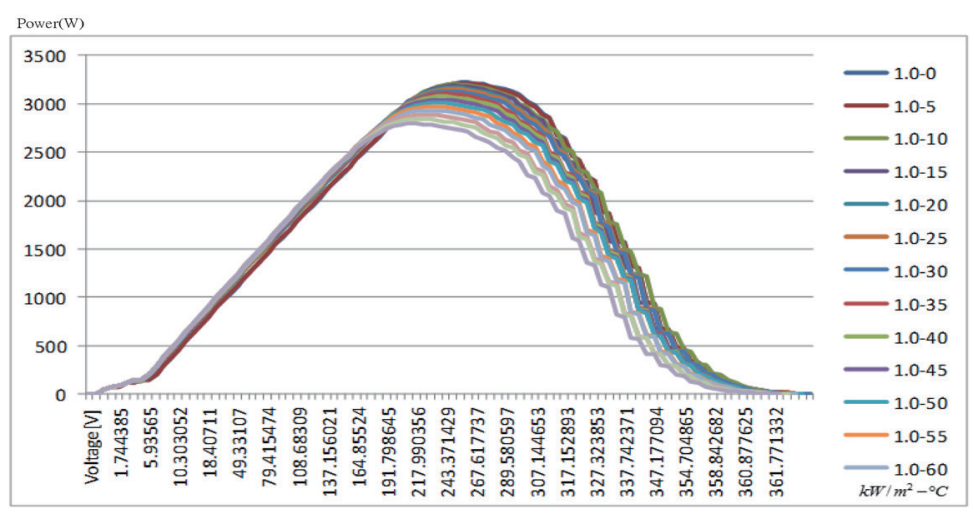

Fig. 2. (Color online) Photovoltaic module array $P-V$ curves at different module temperatures.

A CMAC excites a corresponding memory when it receives input signals of different sizes. Similar input signals excite similar memories, and store weight values in the memory addresses. The input signal and the corresponding output signal relationship are stored directly in the memory cells, so the memory capacity required is large. However, an individual input signal does not use all the memory, and may actually use only a small amount of it. This is what happens in the human cerebellum. Although memory content can be very large for a specific event, only a small part of the memory is used for immediate reaction and resolution. In CMAC correspondence, each memory address stores a weight, and when a group of signals is input, they will be quantified, reencoded, and combined with the excitation addresses. Then, it will be excited to a set of memory addresses, and finally, the sum of the weight values in the address of the excited memory will determined to obtain an output corresponding to the input signal. After the resulting output value is compared with the original ideal value, the average of the error value is assigned to a group of excited memory addresses for adjustment, and data training can be completed.

(1) Quantification: The idea of converting an input signal to an analog signal is the same as that of a general analog-to-digital IC function. This conversion relationship is shown in Eq. (1).

$$
Q_{x}(x)=\operatorname{ceil}\left(\left(x-x_{\min }\right) /\left[\left(x_{\max }-x_{\min }\right) / Q_{\max }\right]\right)
$$

$x$ : Quantized input signal

$Q_{\max }:$ Maximum quantization level

ceil: Largest integer

$x_{\max }$ : Maximum value of the training sample

$x_{\text {min }}$ : Minimum value of the training sample

The maximum and minimum values of the input data are divided into quantification levels of several regions in an equidistant manner. If precise quantification is necessary, the memory space increases, but a higher resolution can be obtained. ${ }^{(18)}$ The text-based maximum and minimum values will be equally divided over 16 regions from 0 to 15 . Any value above the maximum will go into region 15 and any value lower than the minimum will go into region 0 . Values between the maximum and the minimum will be equidistantly divided to give the corresponding quantized values. 
(2) Excitation address encoding: The input signal levels are converted to corresponding binary numbers and then combined and encoded. The input condition signals used in this study are power, voltage, and slope change rate. After quantization, the levels are $(5,10,8,12)$, the quantized binary values being $\left(0101_{b}, 1010_{b}, 1000_{b}, 1100_{b}\right)$, combined and encoded as $(\underline{1100}$ $\underline{1000} \underline{1010} \underline{0101}$ b). Finally, if 3 bits are grouped, they can be divided into 6 groups. From the least significant bit (LSB) to the most significant bit (MSB), the sequentially coded excitation addresses are 6 , so after learning the rearranged excitation address, it is converted to the relative memory position corresponding to the decimal value, $x_{1}=101_{\mathrm{b}}=5, x_{2}=100_{\mathrm{b}}=4$, $x_{3}=010_{\mathrm{b}}=2, x_{4}=100_{\mathrm{b}}=4, x_{5}=100_{\mathrm{b}}=4$, and $x_{6}=001_{\mathrm{b}}=1$. If it is assumed that the initial weight of all the memories is 0 , then the sum of $w_{1}^{5}, w_{2}^{4}, w_{3}^{2}, w_{4}^{4}, w_{5}^{4}$, and $w_{6}^{1}$ is 0 when added.

(3) Weight adjustment: Because the output destination of the CMAC used in this study is 1, which has a clear target value, the supervised learning method is used; however, adjusting the respective weight values uses the steepest descent, as shown in Eq. (2).

$$
w_{i(\text { new })}^{x_{i}}=w_{i(o l d)}^{x_{i}}+\beta \frac{Y_{d}-Y}{A^{*}}, \quad i=1,2, \ldots, x^{*}
$$

(4) Fault tolerance: This CMAC has good anti-interference characteristics. Take the 16-

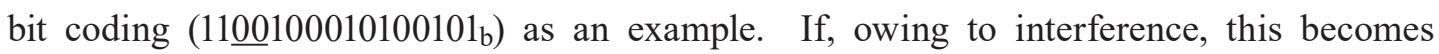
(1101100010100101 $)$, after encoding, the excitation address $\left(x_{6}, x_{5}, x_{4}, x_{3}, x_{2}, x_{1}\right)$ will change from $(1,4,4,2,4,5)$ to $(1,5,4,2,4,5)$. Only $x_{5}$ generates an error output, the others being normal, demonstrating fault tolerance. If the clustering number is increased, storage can be more dispersed. Thus even in the event of error detection, the impact on the output signal will be low and the output weight values will be more reliable. A framework diagram of the CMAC is shown in Fig. 3.

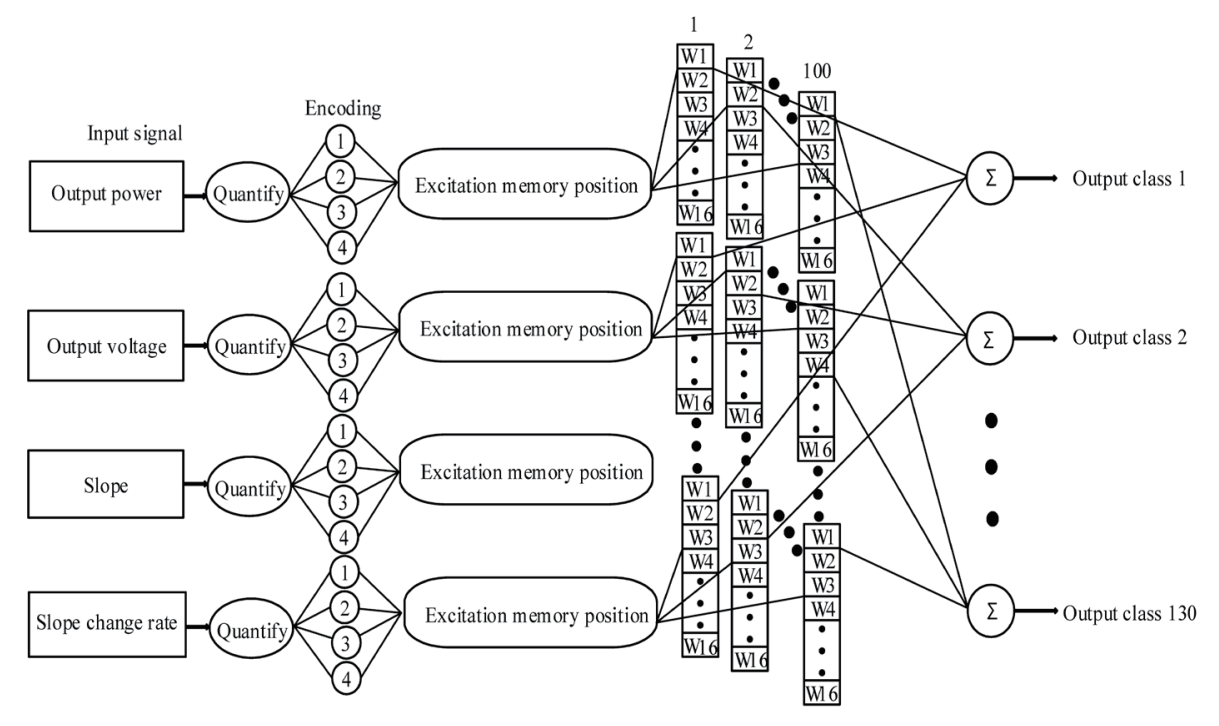

Fig. 3. Cerebellar model articulation controller. 
The CMAC training process is shown in Fig. 4. The first step is quantitative analysis, then a combination of reencoding, group encoding, and excitation to the corresponding memory address for the input of the training samples, and weight values are added within the excitation address. Finally, the weight value of the output found can be adjusted using Eq. (2) to achieve the set target value. If the weight value reaches the set target value, the training process ends prematurely. Training should not end until the training number has been reached.

The method proposed here combines the concept of the $P-V$ characteristic curve slope. When the amount of solar radiation or the temperature of the array changes, this is reflected by changes in the output $P-V$ characteristic curve and this allows the MPP to be more accurately determined. As shown in Fig. 5, when the solar radiation quantities are 0.8, 0.9, and $1 \mathrm{~kW} / \mathrm{m}^{2}$ and the temperature of the solar array module is constant at $75^{\circ} \mathrm{C}$, the characteristic curve overlaps, as shown in the figure. Tracking errors can easily arise, and hence, the $P-V$ characteristic curve is not a reliable method for the determination of the MPP. However, the addition of the slope and rate of slope change allows the rapid control of the MPP, and also increases the accuracy

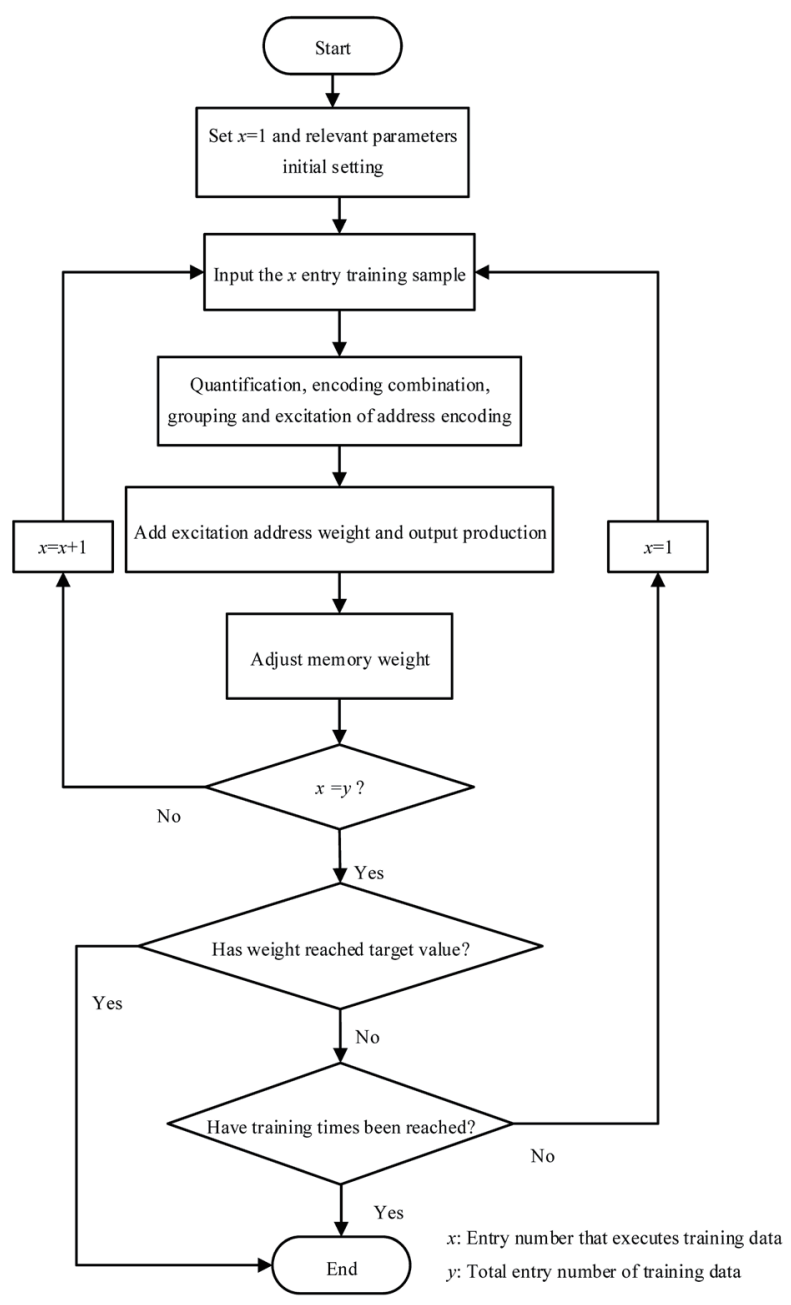

Fig. 4. Cerebellar model articulation controller learning flow. 




Fig. 5. (Color online) $P-V$ characteristics with different amounts of solar radiation at constant temperature.

of tracking by using two more judgment conditions; this improves the overall power generation efficiency.

As shown in Fig. 6, the slope $e$ and the amount of slope change $\dot{e}$ are used to divide the $P-V$ characteristic curve into 5 portions for analysis, wherein the slope $e \triangleq \frac{P_{P V}(x+1)-P_{p v}(x)}{V_{p v}(x+1)-V_{p v}(x)}$ and slope error amount $\dot{e} \triangleq e(x+1)-e(x)$.

(1) $e>0, \dot{e}>0$ : The output power and voltage of the working point are to the left of the MPP, and the direction is towards the position opposite to the MPP.

(2) $e>0, \dot{e}<0$ : The output power and voltage of the working point are to the left of the MPP, and the direction is towards the position of the MPP.

(3) $e<0, \dot{e}>0$ : The output power and voltage of the working point are to the right of the MPP, and the direction is towards the position of the MPP.

(4) $e<0, \dot{e}<0$ : The output power and voltage of the working point are to the right of the MPP, and the direction is opposite to the position of the MPP.

(5) $e=0$ : The operating point is at the MPP.

\section{Measured Results of MPPT}

In this study, we used the Sharp NT-R5E3E modules connected in 9 series and 2 parallel arrangements with sunshine intensity from 0.1 to $1 \mathrm{~kW} / \mathrm{m}^{2}$, at $0.1 \mathrm{k} / \mathrm{m}^{2}$ intervals, over a temperature range of $0-75^{\circ} \mathrm{C}$ at intervals of $5{ }^{\circ} \mathrm{C}$. A CMAC with a characteristic curve slope and slope change rate was used to perform MPPT. The test allowed the position of the MPP to be determined. The position of the MPP at different solar intensities, and the PV module temperature were quite different. The proposed method requires input samples, and CMAC training. The voltage, power, slope, and rate of change of the slope are used as input signals, and by training, the duty cycle needed by the boost converter could be determined, which allows the control and tracking of the MPP. 


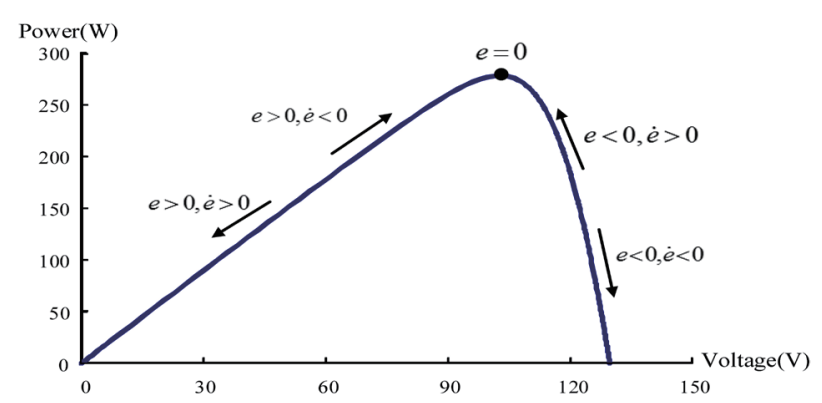

Fig. 6. Map for judging the relationship among the output $P-V$ characteristic curve, slope, and slope change rate.

\subsection{Architecture of PV module array power generation system}

Changes in external environmental conditions, such as the amount of sunlight or array temperature, change the $P-V$ output curve. The method proposed in this paper compensates for these changes in output and can quickly identify the position of the MPP and adjust the duty cycle $D$ to control the MPP voltage to achieve MPPT. The test framework is shown in Fig. 7 and comprises a $3 \mathrm{~kW}$ PV power generation system that uses Sharp NT-R5E3E modules connected in 9 series and 2 parallel arrangements. This is a domestic-type system that can be used for family dwellings. The architecture of the cerebellar model described in this paper is shown in Fig. 7. The system allows MPPT of the PV module array via a general boost converter with a MPPT algorithm. In a typical boost converter, the duty cycle $D$ corresponds to an output voltage. By using this principle, the converter can keep the PV module array at its MPP.

\subsection{MPPT of CMAC}

In this study, the slope and the slope change rate of the $P-V$ characteristic curves were used to track the maximum power. Figure 8 is a graph showing the $P-V$ curve output map of a tested PV module array. The sunshine intensity was $0.4 \mathrm{~kW} / \mathrm{m}^{2}$ at a temperature of $75{ }^{\circ} \mathrm{C}$. The horizontal ordinate voltage $(V)$ traces the $P-V$ curve formed by the voltage at numerous points, one of which is at the maximum power output. The characteristic curve relationship can be used as the MPPT target for the controller. The sunshine intensities were from 0.1 to $1 \mathrm{~kW} / \mathrm{m}^{2}$, in steps of $0.1 \mathrm{~kW} / \mathrm{m}^{2}$ at temperatures of the PV module array ranging from 0 to $75{ }^{\circ} \mathrm{C}$, in steps of $5{ }^{\circ} \mathrm{C}$. A total of 176 data samples were collected for training, and the training parameters used for model articulation were as follows:

(1) Input settings: output power, output voltage, slope, and rate of change with slope

(2) Quantization level: 16

(3) Group bit number: 4 bits

(4) Number of groups: 4

(5) Learning constant $(\beta): 1$ 


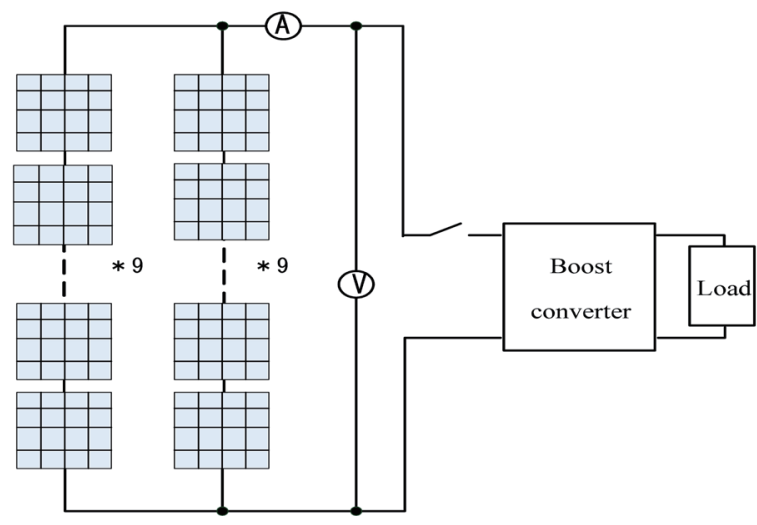

Fig. 7. (Color online) 9 series 2 parallel PV module array.

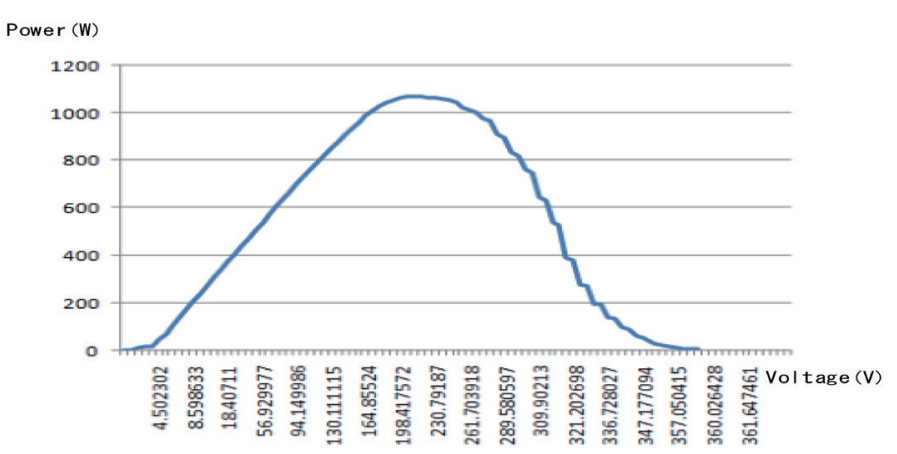

Fig. 8. (Color online) $P-V$ curve with sunlight intensity of $0.4 \mathrm{~kW} / \mathrm{m}^{2}$ and array temperature of $75^{\circ} \mathrm{C}$.

(6) Training cycles: 10

From the output $P-V$ characteristic data obtained under different conditions of sunlight and temperatures, the MPPT of the PV module array can be achieved after training via the CMAC. The flow execution steps are as follows.

(1) Use data from each $P-V$ curve for network training. The weight value of the CMAC was obtained after completion.

(2) Enter the test sample.

(3) Quantify the data.

(4) Recode the combination.

(5) Enter the number of groups.

(6) Excite the encoding of the address.

(7) Produce an output by adding the weight value in the memory address that was excited.

(8) Judge the output weight value after adding. If the weight value is close to 1 , the probability of this point being the MPP voltage is high.

(9) Output the result of the MPPT.

Figure 9 shows a MPPT flow chart for the proposed CMAC. The first step is the detection of the output voltage and current, and the calculation of the power. The slope and slope change rate are then calculated using two points, and the other output voltage and current can be generated when the duty cycle $D$ is changed. The slope and slope change rate can then be calculated. These steps allow the voltage value corresponding to the MPP to be accurately determined.

\subsection{Test results}

In this study, the $P-V$ curves under different external environmental conditions were tested. The CMAC was used to track the maximum power. Tests were carried out with 5 different intensities of sunlight and temperatures of the PV module array. The test conditions are listed in Table 1. Finally, the output weight value approaching 1 was used as the MPP position and the 


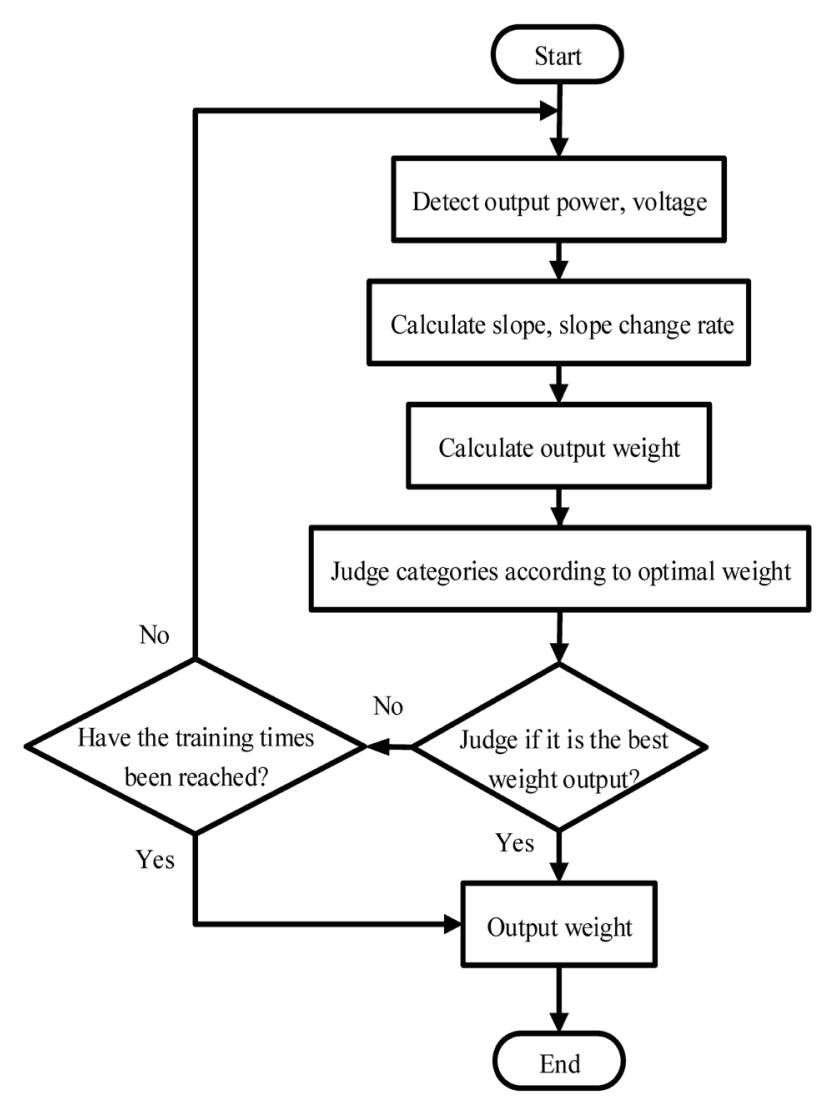

Fig. 9. CMAC maximum power tracking flow chart.
Table 1

PV module array power generation system environmental test conditions.

\begin{tabular}{lc}
\hline Case & Test conditions \\
\hline 1 & Sunlight intensity $0.3 \mathrm{~kW} / \mathrm{m}^{2}$ and array temperature $20^{\circ} \mathrm{C}$ \\
2 & Sunlight intensity $0.5 \mathrm{~kW} / \mathrm{m}^{2}$ and array temperature $35^{\circ} \mathrm{C}$ \\
3 & Sunlight intensity $0.6 \mathrm{~kW} / \mathrm{m}^{2}$ and array temperature $40^{\circ} \mathrm{C}$ \\
4 & Sunlight intensity $0.7 \mathrm{~kW} / \mathrm{m}^{2}$ and array temperature $50^{\circ} \mathrm{C}$ \\
5 & Sunlight intensity $1.0 \mathrm{~kW} / \mathrm{m}^{2}$ and array temperature $70^{\circ} \mathrm{C}$ \\
\hline
\end{tabular}

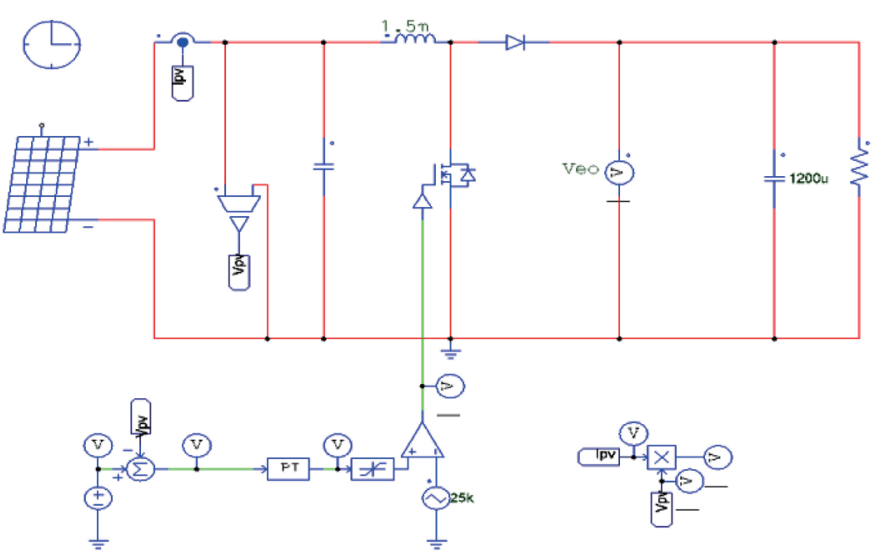

Fig. 10. (Color online) Built circuit of PV power generation.

corresponding MPP position to determine the MPP voltage. The built circuit of the PV power generation system is shown in Fig. 10. The voltage command value of the MPP controls the voltage at the operating point with a simple proportional-integral (PI) controller to reach the maximum power output. Thus, we verified that the CMAC can indeed detect the position of the MPP voltage.

Case 1: Sunlight intensity of $0.3 \mathrm{~kW} / \mathrm{m}^{2}$ and array temperature of $20^{\circ} \mathrm{C}$.

Figure 11 shows the $P-V$ characteristic curve of Case 1 input conditions. The MPPT on both sides of the MPP is represented as points 1 and 2. From Table 2, it can be seen that the output of the maximum weight value falls at point 73 , and the corresponding voltage is $318.08 \mathrm{~V}$. Finally, the test result was used to verify that the voltage at this position was indeed the MPP voltage. The measured results are shown in Fig. 12.

Case 2: Sunlight intensity of $0.5 \mathrm{~kW} / \mathrm{m}^{2}$ and array temperature of $35^{\circ} \mathrm{C}$.

Figure 13 shows the $P-V$ characteristic curve of Case 2 input conditions. The MPPT on both sides of the MPP is represented as points 1 and 2. From Table 3, it can be seen that the output of the maximum weight value falls at point 78 , and the corresponding voltage is $312.20 \mathrm{~V}$. Finally, the test result was used to verify that the voltage at this position was indeed the MPP voltage. The measured results are shown in Fig. 14. 


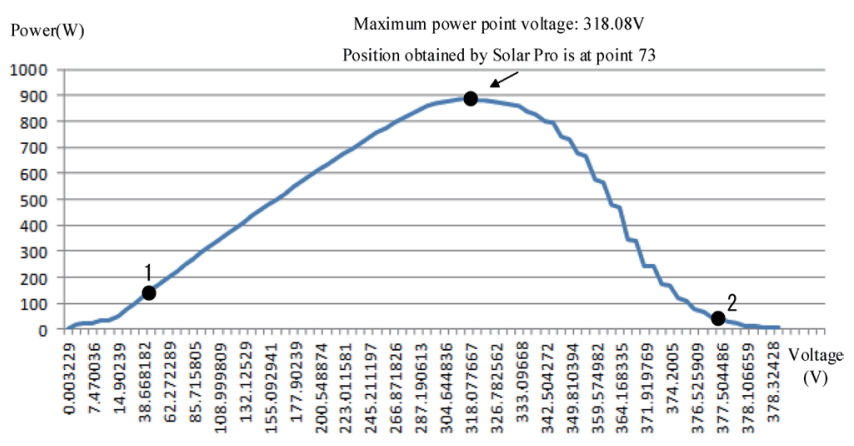

Fig. 11. (Color online) $P-V$ curve graph with sunlight intensity of $0.3 \mathrm{~kW} / \mathrm{m}^{2}$ and array temperature of $20{ }^{\circ} \mathrm{C}$.

Table 2

Test of maximal power tracking by the CMAC for Case 1.

\begin{tabular}{llll}
\hline Data point number & & \multicolumn{1}{c}{1} & \multicolumn{1}{c}{2} \\
\hline & $\mathrm{W}_{70}$ & 0 & 0 \\
& $\mathrm{~W}_{71}$ & 0 & 0.0462 \\
& $\mathrm{~W}_{72}$ & 0.6667 & 0.31 \\
Output weight value & $\mathrm{W}_{73}$ & $\mathbf{0 . 9 7 3 8}$ & $\mathbf{1 . 0 8 7 7}$ \\
& $\mathrm{W}_{74}$ & 0.5553 & 0 \\
& $\mathrm{~W}_{75}$ & 0.16 & 0 \\
& $\mathrm{~W}_{76}$ & 0 & 0 \\
Known categories & & $\mathrm{W}_{73}$ & $\mathrm{~W}_{73}$ \\
Simulation results & & $\mathrm{W}_{73}$ & $\mathrm{~W}_{73}$ \\
\hline
\end{tabular}

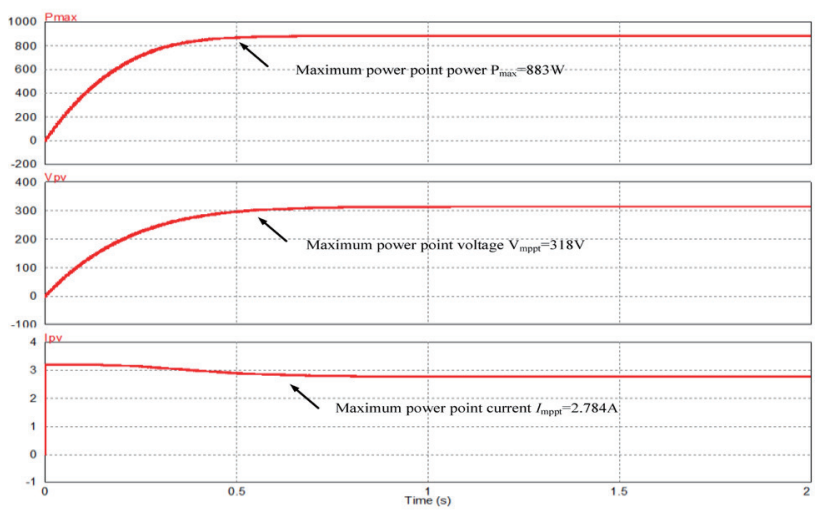

Fig. 12. (Color online) Output power, voltage, and current during MPPT for Case 1.

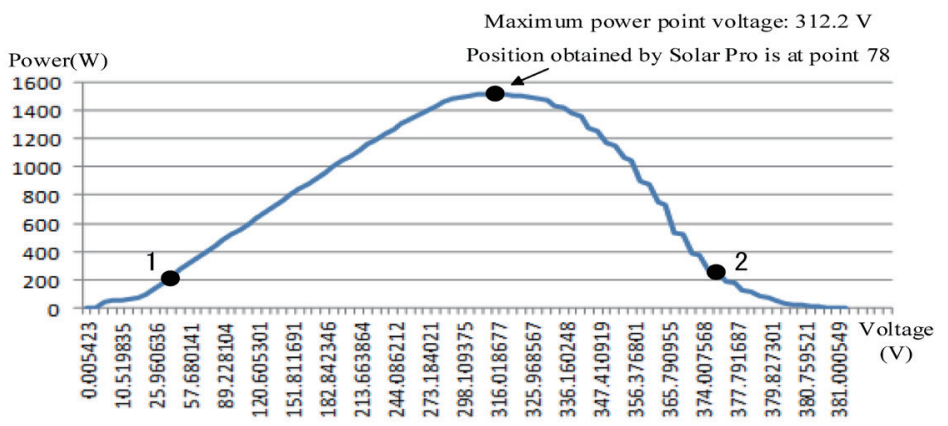

Fig. 13. (Color online) $P-V$ curve graph with sunlight intensity of $0.5 \mathrm{~kW} / \mathrm{m}^{2}$ and array temperature of $35{ }^{\circ} \mathrm{C}$.

Table 3

Test of maximal power tracking by the CMAC for Case 2 .

\begin{tabular}{llll}
\hline Data point number & & \multicolumn{1}{c}{1} & \multicolumn{1}{c}{2} \\
\hline & $\mathrm{W}_{75}$ & 0 & 0 \\
& $\mathrm{~W}_{76}$ & 0 & 0 \\
& $\mathrm{~W}_{77}$ & 0.6667 & 0.6685 \\
Output weight value & $\mathrm{W}_{78}$ & $\mathbf{0 . 9 2 5 8}$ & $\mathbf{1 . 0 9 1 1}$ \\
& $\mathrm{W}_{79}$ & 0.9137 & 0 \\
& $\mathrm{~W}_{80}$ & 0.0517 & 0 \\
& $\mathrm{~W}_{81}$ & 0 & 0 \\
Known categories & & $\mathrm{W}_{78}$ & $\mathrm{~W}_{78}$ \\
Simulation results & & $\mathrm{W}_{78}$ & $\mathrm{~W}_{78}$ \\
\hline
\end{tabular}

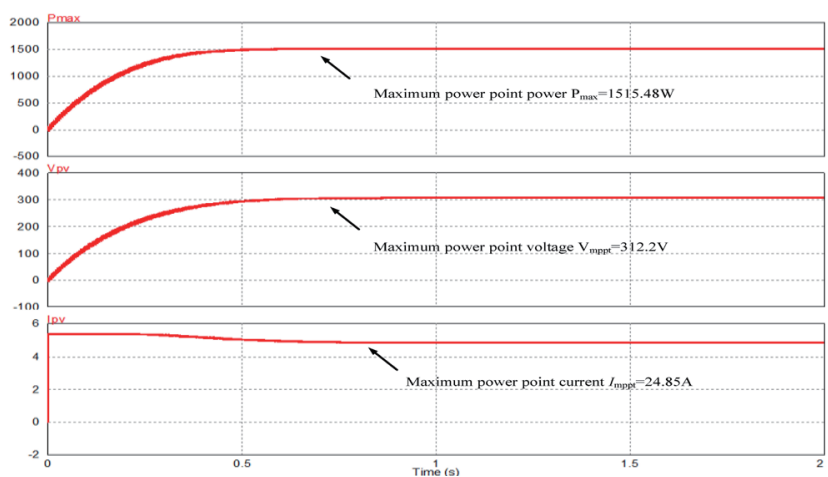

Fig. 14. (Color online) Output power, voltage, and current during MPPT for Case 2. 
Case 3: Sunlight intensity of $0.6 \mathrm{~kW} / \mathrm{m}^{2}$ and array temperature of $40{ }^{\circ} \mathrm{C}$.

Figure 15 shows the $P-V$ characteristic curve of Case 3 input conditions. The MPPT on both sides of the MPP is represented as points 1 and 2. From Table 4, it can be seen that the output of the maximum weight value falls at point 74 , and the corresponding voltage is $312.19 \mathrm{~V}$. Finally, the test result was used to verify that the voltage at this position was indeed the MPP voltage. The measured results are shown in Fig. 16.

Case 4: Sunlight intensity of $0.7 \mathrm{~kW} / \mathrm{m}^{2}$ and array temperature of $50{ }^{\circ} \mathrm{C}$.

Figure 17 shows the $P-V$ characteristic curve of Case 4 input conditions. The MPPT on both sides of the MPP is represented as points 1 and 2. From Table 5, it can be seen that the output of the maximum weight value falls at point 71 , and the corresponding voltage is 304.12 V. Finally, the test result was used to verify that the voltage at this position was indeed the MPP voltage. The measured results are shown in Fig. 18.

Case 5: Sunlight intensity $1 \mathrm{~kW} / \mathrm{m}^{2}$ and array temperature $70{ }^{\circ} \mathrm{C}$.

Figure 19 shows the $P-V$ characteristic curve of Case 5 input conditions. The MPPT on both sides of the MPP is represented as points 1 and 2. From Table 6 it can be seen that the output of the maximum weight value falls at point 67 , and the corresponding voltage is $283.47 \mathrm{~V}$. Finally, the test result was used to verify that the voltage at this position was indeed the MPP voltage. The measured results are shown in Fig. 20.

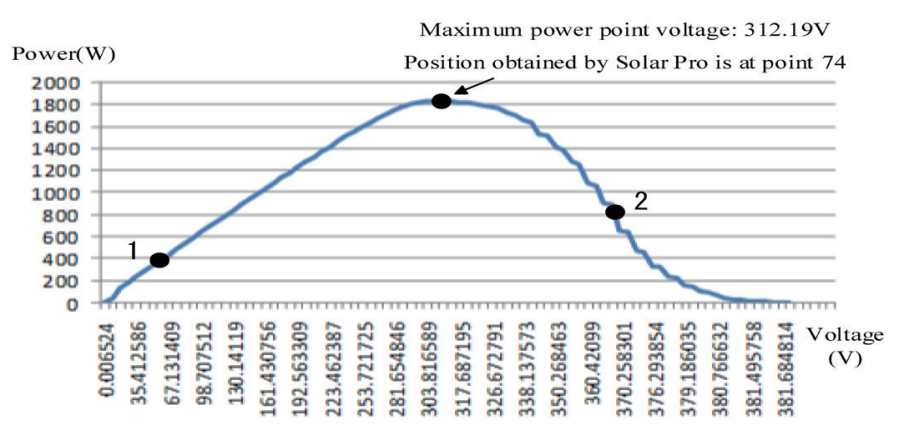

Fig. 15. (Color online) $P-V$ curve graph with sulight intensity of $0.6 \mathrm{~kW} / \mathrm{m}^{2}$ and array temperature of $40{ }^{\circ} \mathrm{C}$.

Table 4

Test of maximal power tracking by the CMAC for Case 3 .

\begin{tabular}{llll}
\hline Data point number & & \multicolumn{1}{c}{1} & \multicolumn{1}{c}{2} \\
\hline & $\mathrm{W}_{71}$ & 0 & 0 \\
& $\mathrm{~W}_{72}$ & 0 & 0 \\
& $\mathrm{~W}_{73}$ & 0.6667 & 0.6721 \\
Output weight value & $\mathrm{W}_{74}$ & $\mathbf{0 . 9 2 1 5}$ & $\mathbf{0 . 9 0 0 3}$ \\
& $\mathrm{W}_{75}$ & 0.9117 & 0 \\
& $\mathrm{~W}_{76}$ & 0.636 & 0 \\
& $\mathrm{~W}_{77}$ & 0 & 0 \\
Known categories & & $\mathrm{W}_{74}$ & $\mathrm{~W}_{74}$ \\
Simulation results & & $\mathrm{W}_{74}$ & $\mathrm{~W}_{74}$ \\
\hline
\end{tabular}

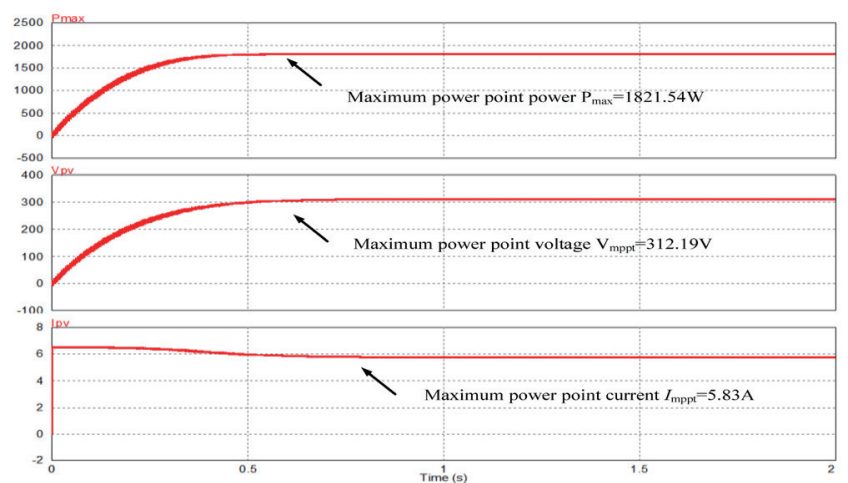

Fig. 16. (Color online) Output power, voltage, and current during MPPT for Case 3. 


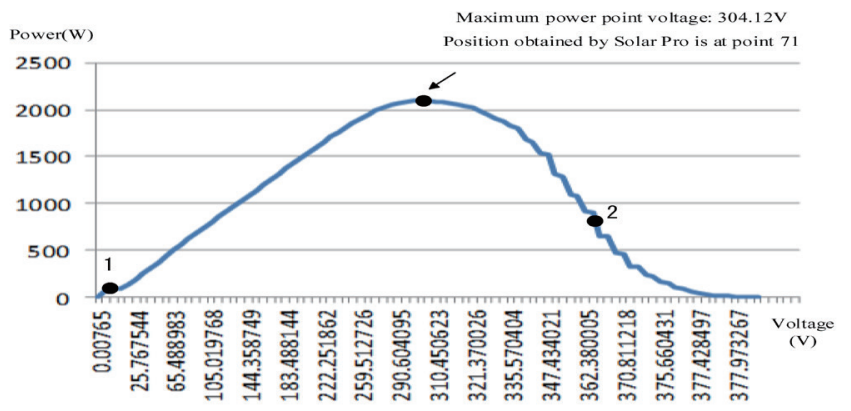

Fig. 17. (Color online) $P-V$ curve graph with sunlight intensity of $0.7 \mathrm{~kW} / \mathrm{m}^{2}$ and array temperature of $50{ }^{\circ} \mathrm{C}$.

Table 5

Test of maximal power tracking by CMAC for Case 4.

\begin{tabular}{llll}
\hline Data point number & & \multicolumn{1}{c}{1} & \multicolumn{1}{c}{2} \\
\hline & $\mathrm{W}_{69}$ & 0 & 0 \\
& $\mathrm{~W}_{70}$ & 0.8333 & 0.6339 \\
& $\mathrm{~W}_{71}$ & $\mathbf{0 . 9 6 8 8}$ & $\mathbf{0 . 9 7 4 7}$ \\
Output weight value & $\mathrm{W}_{72}$ & 0.5666 & 0 \\
& $\mathrm{~W}_{73}$ & 0.1451 & 0 \\
& $\mathrm{~W}_{74}$ & 0 & 0 \\
& $\mathrm{~W}_{75}$ & 0 & 0 \\
Known categories & & $\mathrm{W}_{71}$ & $\mathrm{~W}_{71}$ \\
Simulation results & & $\mathrm{W}_{71}$ & $\mathrm{~W}_{71}$ \\
\hline
\end{tabular}

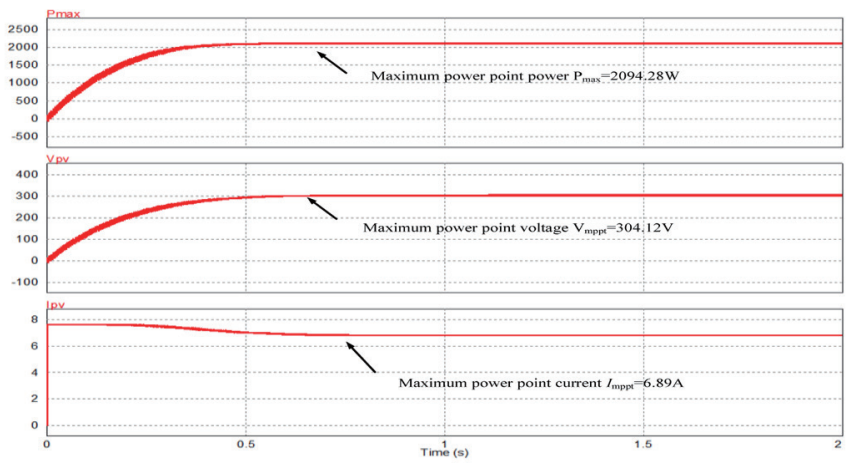

Fig. 18. (Color online) Output power, voltage, and current during MPPT for Case 4.

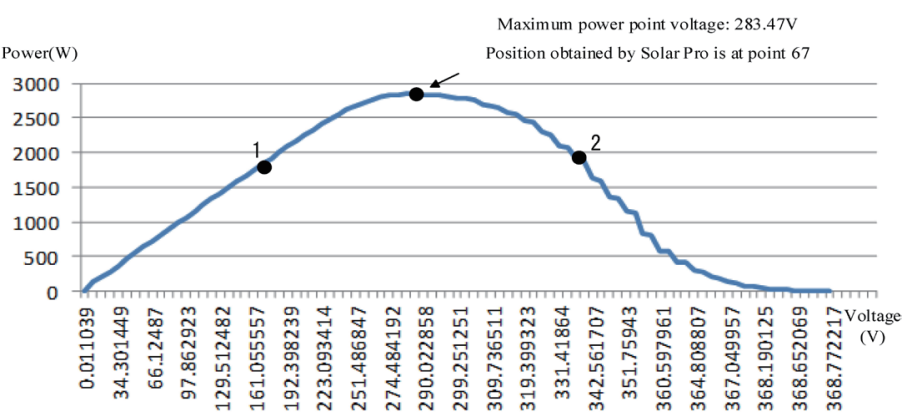

Fig. 19. (Color online) $P-V$ curve graph with sunlight intensity of $1 \mathrm{~kW} / \mathrm{m}^{2}$ and array temperature of $70{ }^{\circ} \mathrm{C}$.

Table 6

Test of maximal power tracking by CMAC for Case 5.

\begin{tabular}{llll}
\hline Data point number & & \multicolumn{1}{c}{1} & \multicolumn{1}{c}{2} \\
\hline & $\mathrm{W}_{64}$ & 0 & 0 \\
& $\mathrm{~W}_{65}$ & 0.6667 & 0 \\
& $\mathrm{~W}_{66}$ & 0.8851 & 0.4631 \\
Output weight value & $\mathrm{W}_{67}$ & $\mathbf{1 . 0 9 4 0}$ & $\mathbf{0 . 9 6 9 2}$ \\
& $\mathrm{W}_{68}$ & 0.6700 & 0 \\
& $\mathrm{~W}_{69}$ & 0 & 0 \\
& $\mathrm{~W}_{70}$ & 0 & 0 \\
Known categories & & $\mathrm{W}_{67}$ & $\mathrm{~W}_{67}$ \\
Simulation results & & $\mathrm{W}_{67}$ & $\mathrm{~W}_{67}$ \\
\hline
\end{tabular}

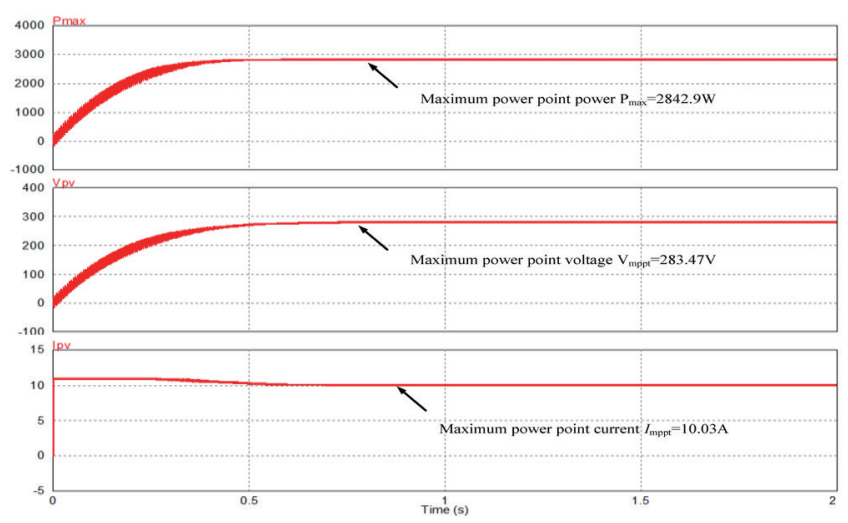

Fig. 20. (Color online) Output power, voltage, and current during MPPT for Case 5. 


\section{Conclusions}

In this study, a method was developed for the tracking and control of the maximum power output of a PV module array by CMAC. The controller changes the output voltage to achieve the maximum power output using the duty cycle of the boost converter. Tests were carried out for several different measured MPP voltages prevailing under different sunlight intensities and module array temperatures. However, PV power generation systems are vulnerable to environmental changes and these are not evenly spread over the daylight hours. The MPPT method is used to enable the PV power generation system to maintain an MPP output at all times. A CMAC that can quickly learn the correct MPP voltage of the $P-V$ characteristic curve, thus allowing the control of the PV generation system to output maximum power, was presented. The controller training times were short and the test results verified the feasibility of this MPPT method.

\section{References}

1 N. Femia, G. Lisi, G. Petrone, G. Spagnuolo, and M. Vitelli: IEEE Trans. Ind. Electron. 55 (2008) 2610. https:// doi.org/10.1109/TIE.2008.924035

2 M. A. S. Masoum, H. Dehbonei, and E. F. Fuchs: IEEE Trans. Energy Convers. 17 (2002) 514. https://doi. org/10.1109/TEC.2002.805205

3 E. Koutroulis, K. Kalaitzakis, and N. C. Voulgaris: IEEE Trans. Power Electron. 16 (2001) 46. https://doi. org $/ 10.1109 / 63.903988$

4 L. Wu, Z. Zhao, and J. Liu: IEEE Trans. Energy Convers. 22 (2007) 881. https://doi.org/10.1109/ TEC.2007.895461

5 K. L. Lian, J. H. Jhang, and I. S. Tian: IEEE J. Photovoltaics 4 (2014) 626. https://doi.org/10.1109/ JPHOTOV.2013.2297513

6 W. Gao, S. Liu, and L. Huang: J. Comput. Appl. Math. 236 (2012) 2741. https://doi.org/10.1016/J.CAM.2012.01.013

7 S. Daraban, D. Petreus, and C. Morel: IEEE IECON 2013 39th Annu. Conf. Industrial Electron. Society (2013) 1490-1495. https://doi.org/10.1109/IECON.2013.6699353

8 M. Dorigo, M. Birattari, and T. Stutzle: IEEE Comput. Intell. Mag. 1 (2006) 28. https://doi.org/10.1109/ MCI.2006.329691

9 G. Iacca, R. Mallipeddi, E. Mininno, F. Neri, and P. N. Suganthan: IEEE SDE (2011) 11-15. https://doi. org/10.1109/SDE.2011.5952051

10 Y. Liu and B. Niu: Int. J. Photoenergy 2012 (2012) 1. https://doi.org/10.1155/2012/530139

11 A. Liu, E. Zahara, and M. T. Yang: Int. J. Photoenergy 2012 (2012) 1. https://doi.org/10.1155/2012/791373

12 K. Sundareswaran, P. Sankar, P. S. R. Nayak, S. P. Simon, and S Palani: IEEE Trans. Energy Convers. 6 (2014) 198. https://doi.org/10.1109/TSTE.2014.2363521

13 J. Lian and D. L. Maskell: IEEE Symp. Comput. Intell. Appl. Smart Grid (2014) 1-8. https://doi.org/10.1109/ CIASG.2014.7011560

14 M. F. N. Tajuddin, S. M. Ayob, and Z. Salam: IEEE Int. Conf. Power Energy (2012) 384-389. https://doi. org/10.1109/PECon.2012.6450242

15 R. Storn: Proc. North Am. Fuzzy Information Process. (1996) 519-523. https://doi.org/10.1109/ NAFIPS.1996.534789

16 J. S. Albus: J. Dyn. Syst. Meas. Contr. 97 (1975) 220. https://doi.org/10.1115/1.3426922

17 C. P. Hung, W. G. Liu, and H. Z. Su: Proc. the 5th Int. Conf. Intell. Comput. (2009) 724-734

18 H. Zazo, E. D. Castillo, J. F. Reynaud, and R. Leyva: Energies 5 (2012) 2653. https://doi.org/10.3390/ en5082652 


\section{About the Authors}



Kuei-Hsiang Chao was born in Tainan, Taiwan, in 1962. He received his B.S. degree in electrical engineering from National Taiwan Institute of Technology, Taipei, Taiwan, in 1988, and his M.S. and Ph.D. degrees in electrical engineering from National Tsing Hua University, Hsinchu, Taiwan, in 1990 and 2000, respectively. He is presently a professor at the National Chin-Yi University of Technology, Taichung, Taiwan. His areas of interest are computer-based control systems, applications of control theory, renewable energy, and power electronics. He is a life member of the Solar Energy and New Energy Association and a member of the IEEE.

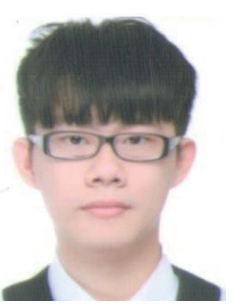

Yu-Hsiang Liao was born in Tainan, Taiwan, in 1994. He received his B.S. degree in electrical engineering from National Chin-Yi University of Technology, Taichung, Taiwan, in 2016. He is currently a graduate student in the Department of Electrical Engineering of National Chin-Yi University of Technology. His research interests include photovoltaic power systems and power electronics design.

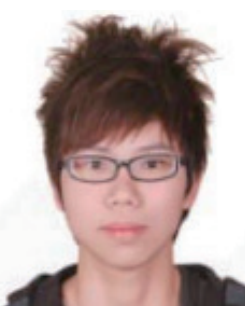

Ming-Chang Tseng was born in Kaohsiung, Taiwan, in 1988. He received his B.S. degree in electrical engineering from Cheng Shiu University of Technology, Kaohsiung, Taiwan, in 2010, and his M.S. degree in electrical engineering from National Chin-Yi University of Technology in 2016. He is presently an engineer in HiTRON Electronics Corporation. His research interests include photovoltaic power systems and power converters. 